\title{
Applications of Myostatin (MSTN) Gene in the Livestock Animals and Humans: A Review
}

\author{
Wani A. Ahad", Mudasir Andrabi, Sajad A. Beigh, Rumase A. Bhat and Riaz A. Shah \\ Faculty of Veterinary Sciences and Animal Husbandry, Sher-e-Kashmir University of \\ Agricultural Sciences and Technology of Kashmir, Shuhama Alusteng, India \\ *Corresponding author
}

\section{A B S T R A C T}

\begin{tabular}{|l|}
\hline Ke y w o r d s \\
MSTN, Growth and \\
differentiation \\
factor 8, Double \\
muscling, GDF8, \\
Myostatin.
\end{tabular}

Polymorphism is found in almost all livestock animals including poultry and occurs at all levels of genetic organization from DNA sequence to major morphological traits in livestock animals. Genetic polymorphism contributes to the phenotype variability in animals and is an essential component of genetic improvement of the livestock animals. The genetic variations in livestock animals for meat production create a great interest to the researchers and had been used by them in Marker Assisted Selection (MAS) to identify animals with specific beneficial production traits and there after selecting mating pairs based on these traits. The polymorphism in animals at gene level may arise due to changes in nucleotides. The goal of polymorphism at the gene level is to locate and precisely describe changes in DNA sequences that are responsible for variation among the different phenotypes. Myostatin (MSTN/GDF8) is a member of transforming growth factor- $\beta$ super family. It is produced by skeletal muscle and acts as a negative regulator of muscle growth. It has an essential role in the regulation of muscle growth and meat quality. As a result, MSTN gene is primarily responsible for muscle growth and development and could be a potential candidate gene marker for animal muscular growth.

\section{Introduction}

The TGF- $\beta$ superfamily is a large group of proteins that regulate growth, differentiation and apoptosis. One subclass within the TGF- $\beta$ superfamily are growth and differentiation factors (GDFs). Myostatin or growth and differentiation factor 8 (GDF8) is encoded by the gene MSTN. It is synthesized in skeletal muscle cells and inhibits myogenesis [1].

Myostatin mutants are found in whippets, humans, and cows. Myostatin plays a critical role in myogenic differentiation and that the muscular hyperplasia and hypertrophy seen in animals that lack functional myostatin is due to deregulated proliferation and differentiation of myoblasts [2] [3]. Myostatin is a key regulator of skeletal muscle growth and development and is a member of the transforming growth factor- $\beta$ (TGF- $\beta$ ) superfamily. GDF8 is restricted to skeletal muscle in embryogenesis but can also be found in the mammary glands, heart, and adipose tissue in adults. It was discovered in 1997 by Geneticists Se-Jin Lee and McPherron when they created "Mighty Mice". Myostatin is a GDF whose knockout in mice resulted in skeletal muscle hypertrophy and hyperplasia [1]. 


\section{Muscle development and myogenesis}

Embryonic formation of muscle fibers or myogenesis, begins with mesenchymal precursor cells. These cells first commit to the myogenic lineage by expressing muscle regulatory factors (MRFs) and proliferate, forming a pool of myoblasts.

The purpose of myogenic regulatory factors (MRFs) is to stop proliferation and induce differentiation. Expression of the transcription factor, Pax-3, promotes expression of these myogenic differentiation factors, including MyoD and Mrf5 [2].

MyoD up-regulates p21, a cyclin dependent kinase inhibitor that prevents phosphorylation of the retinoblastoma protein $(\mathrm{Rb})$ [2] [4].Phosphorylated $\mathrm{Rb}(\mathrm{pRb})$ inhibits cell cycle progression. Myoblasts then withdraw from the cell cycle and are terminally differentiated. Myoblasts fuse to form myotubes with centralized nuclei, and they accumulate myofibrils (contractile apparatus) and mature into functional muscle cells [2] [4].There are various genes that effect the muscle growth in animals, some of them are in shown in figure 1 .

\section{MSTN gene and myostatin protein}

The GDF-8gene in all species of animals has 3 exons and 2 introns (Figure 2) [5]. Myostatin is synthesized by a 376 amino acid precursor protein. The prepropeptide is made up of three domains namely, C-terminal domain or active molecule, Signal Sequence (Cleaved by a proprotein convertase called Furin in the Golgi Apparatus) and N-terminal propeptide domain which will be cleaved at the RSRR site during maturation [1].

Proteasic digestion processing between the propeptide domain and the $\mathrm{C}$-terminal domain results in an $\mathrm{N}$-terminal propeptide and the mature form of myostatin, a 12-kDa carboxyterminal fragment [6]. Both mature and unprocessed myostatinform disulfidelinked dimers. Moreover, the only active form of the protein is the processed myostatin dimer (Figure 2) [7].

\section{Myostatin pathway}

Myostatin/Growth differentiation factor $(M S T N / G D F 8)$ is a member of the transforming growth factor- $\beta$ (TGF- $\beta$ ) superfamily [1]. Myostatin and activin interact and activate a heterodimeric receptor complex with serine-threonine kinase activity, comprising a type II receptor, activin receptor 2 (ACVR2 and ACVR2B), and a type I receptor, activin receptor-like kinase 4 and 5 (ALK4 and ALK5) [1]. Myostatin/activin signaling in myofibers is mediated by phosphorylation and nuclear translocation of Smad2 or Smad3 (Small mothers against decapentaplegic) transcription factors, and formation of heterodimers with Smad4 [8]. Smad4 complex binds to the promoters in the target genes and forms a transcription repressor complex. Myostatin represses the levels of myogenic regulatory factors (MyoD, Myf4, Myf5 and myogenin) leading to the inhibition of myogenic differentiation [1].

Myostatin inhibits myogenic differentiation factor (MyoD) activity and expression via Smad3 resulting the failure of the myoblasts to differentiate into myotubes (Figure 3) [2]. Myostatin also inhibits Akt (Protein Kinase $\mathrm{B} /$ Serine/theronine specific protein kinase).

That is responsible to cause muscle hypertrophy through activation of protein synthesis [9]. Furthermore, MSTN has been shown to directly prevent Cell Cycle G1 to S phase transition by decreasing the levels of Cyclin dependent kinase complex 2 (CDK2) (Figure 4) [10]. 


\begin{tabular}{|clc|}
\hline S.No. & GENE & CHROMOSOME \\
\hline $\mathbf{1}$ & MSTN: Myostatin (GDF-8) & $\mathbf{2}$ \\
\hline $\mathbf{2}$ & CAST: Calpastatin & $\mathbf{5}$ \\
\hline $\mathbf{3}$ & CLPG: Callipyge & $\mathbf{1 8}$ \\
\hline $\mathbf{4}$ & LEP: Leptin gene & $\mathbf{3}$ \\
\hline $\mathbf{5}$ & Casein: $\alpha$ casein & $\mathbf{6}$ \\
\hline $\mathbf{6}$ & GH: Growth Hormone & $\mathbf{1 9}$ \\
\hline $\mathbf{7}$ & GHR: Bovine Growth Hormone Receptor & $\mathbf{2 0}$ \\
\hline $\mathbf{8}$ & IGF-I: Insulin Like Growth Factor I & $\mathbf{5}$ \\
\hline $\mathbf{9}$ & POU1F1: Pituitary Specific Transcription Factor-1 & $\mathbf{1}$ \\
\hline & & \\
\hline
\end{tabular}

Figure 1: Genes that effect muscle growth in animals

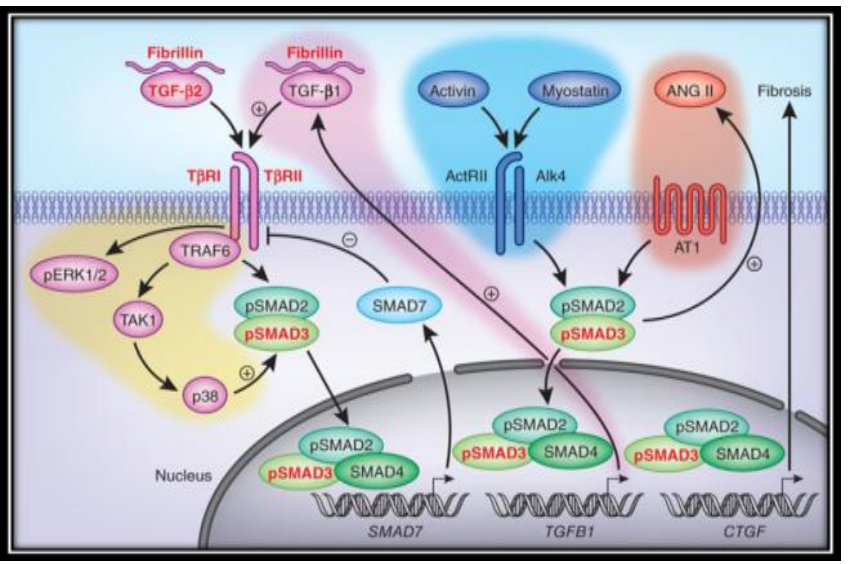

Figure 3: Physiological Action of Myostatin

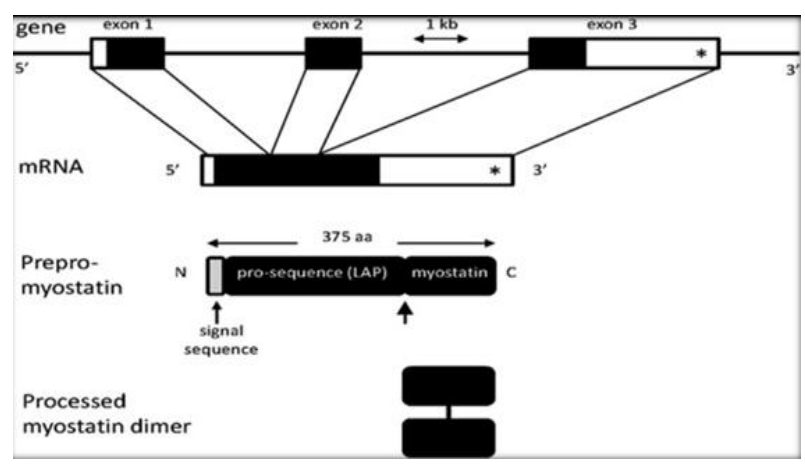

Figure 2: Processed myostatin dimer

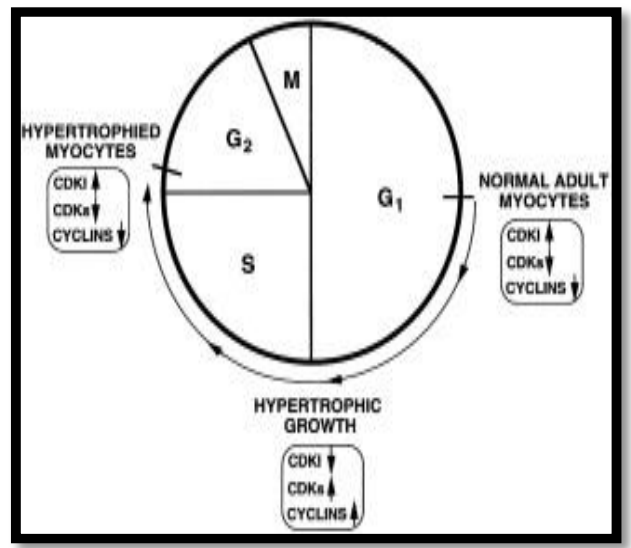

Figure 4: Cell Cycle

\section{MSTN gene polymorphism}

Polymorphism in the myostatingene can supress its expression and may lead to the production of a non-functional protein, which may lead to the increased muscularity or a "double-muscling" character in many species of animals including humans [11]. It has been considered as an important candidate gene for growth and development of domestic animals [12]. MSTN has a key role in muscle growth and is believed to have potential applications in breeding and animal husbandry [12].

Natural myostatin mutations can occur as well: McPherron et al., [1] found in Belgian Blue and Piedmontese cattle a natural myostatin mutation resulting in nonfunctional myostatin and increased muscle size. Myostatin function is highly conserved across vertebrate species [1]. Mutations of the gene result in hyper-muscular phenotypes observed in cattle [1] [13] [14], humans [15], sheep [16] and dogs [17]. Animals without functional myostatin exhibit primarily hyperplasia- an increase in the number of muscle fibers and to a lesser extent hypertrophy- an increase in the size of muscle fibers [1].MSTN gene is primarily responsible for muscle growth and could be a potential candidate gene marker for animal muscular growth [13]. The single nucleotide polymorphisms (SNPs) with MSTN would provide molecular genetic material for studying the meat performance of goat and its further exploitation for "double muscling" phenomenon [18].The MSTN gene has been considered as an important candidate gene for growth and development of livestock animals because of its key role in muscular growth and its immense application in animal husbandry and allied sectors [19]. 


\section{Myostatin in humans}

Myostatin is a muscle-specific muscle growth inhibitor whose expression is probably controlled by glucocorticoids and anabolic steroids among other. Myostatin binds activin receptors as a dimer [1]. Myostatin binding to specific inhibitory proteins (follistatin, gasp1) can prevent myostatin binding to its receptor. Myostatin binding to the receptor activates the kinase bit of the receptor which causes phosphorylation of Smad2/3. Smad2/3 transport to the nucleus and DNA binding can be modulated by inhibitory and co-Smads.

Smad2/3 probably regulates genes that inhibit muscle growth [2]. Obviously, bodybuilders are very keen to inhibit myostatin in order to promote muscle growth further [20]. There are various products which inhibit myostatin such asMYOSTAT, MYO-ZAP, MYO BLAST, MYO-X. If you have lots of myostatin, you're small. If you don't have it, you're musculous [1].

Increasing muscle growth is beneficial to the meat animal industry and for biomedical research. Altering myostatin function enhances muscle growth. The genetic improvement of animals is a fundamental, incessant, and complex process. Identification of myostatin polymorphisms that can interrupt function. Opens the door for widespread screening of possible carrier animals and breeding strategies that can take advantage of the useful nature of a myostatin knockout while selecting against undesirable companion traits. Plans already underway to screen large numbers of various livestock breeds and species will help producers to identify the mutation within their own herds and develop a breeding strategy to maximize its potential. With these varied approaches to exploiting myostatin mutations may represent a significant gain for several livestock industries.

\section{References}

1.McPherron, A.C. and Lee, S.J. 1997. Double muscling in cattle due to mutations in the myostatin gene. Proceedings of National Academy of Sciences 23:12457-12461.

2.Rehfeldt, C., Fiedler, I., Dietl, G. and Ender, K. 2000. Myogenesis and postnatal skeletal muscle cell growth as influenced by selection. Livestock Production Science 66:177-188.

3.Parker, M.H., Seale, P. and Rudnicki, M.A. 2003. Looking back to the embryo: defining transcriptional networks in adult myogenesis. Nature Reviews Genetics 4:497-507.

4Thomas, M., Langley, B., Berry, C., Sharma, M., Kirk, S., Bass, J. \& Kambadur, R. 2000. Myostatin, a negative regulator of muscle growth, functions by inhibiting myoblast proliferation. The Journal of Biological Chemistry 275:40235-40243.

5.Bellinge, R.H.S., Liberles, D.A., Iaschi, S.P.A. and O'brien, P.A. 2005. Myostatin and its implications on animal breeding. Animal Genetics36:1-6.

6.Lee, S.J. 2004. Regulation of muscle mass by myostatin. Annual Review of Cell and Developmental Biology 20:61-86.

7.Joulia-Ekaza, D. and Cabello G. 2006. Myostatin regulation of muscle development: Molecularbasis, natural mutations, physiopathological aspects. Exp Cell Research312:2401-2414.

8.Zhu, X.Y., Topouzis, S., Liang, L.F. \& Stotish, R.L. 2004. Myostatin signaling through Smad2, Smad3 and Smad4 is regulated by the inhibitory Smad7 by a negative feedback mechanism. Cytokine 26:262-272.

9.Joulia-Ekaza, D. \& Cabello, G. 2006. Myostatin regulation of muscle development: Molecular basis, natural mutations, physiopathological aspects. Experimental CellResearch 312:2401- 
2414.

10.McCroskery, S., Thomas, M., Maxwell, L., Sharma, M. \& Kambadur, R. 2003. Myostatin negatively regulates satellite cell activation and self-renewal. TheJournal of Cell Biology 162:11351147.

11.Grisolia, A.B., D’Angelo, G.T., Porto Neto, L.R. and Siqueira, F. 2009. Myostatin $(G D F 8)$ single nucleotide polymorphisms in Nellore cattle. Genetics and Molecular Research8:822830.

12.Zhang, Z.J., Ling, Y.H., Wang, L.J., Hang, Y.F., Guo, X.F., Zhang, Y.H., Ding, J.P. and Zhang, X.R. 2013. Polymorphisms of the myostatin gene (MSTN) and its relationship with growth traits in goat breeds. Genetics and Molecular Research 12(2):965-971.

13.Grobet, L., Martin, L.J.R., Poncelet, D., Pirottin, D., Brouwers, B., Riquet, J., Schoeberlein, A., Dunner, S., Menissier, F., Massabanda, J., Fries, R., Hanset, R. \& Georges, M. 1997. A deletion in the bovine myostatin gene causes the double muscled phenotype in cattle. Nature Genetics 17:71-74.

14.Grobet, L., Poncelet, D., Royo, L.J., Brouwers, B., Pirottin, D., Michaux, C., Menissier, F., Zanotti, M., Dunner, S., Georges, M. 1998. Molecular definition of an allelic series of mutations disrupting the myostatin function and causing double-muscling in cattle. Mammalian Genome 9:210-213.

15.Schuelke, M., Wagner, K.R., Stolz, L.E., Hübner, C., Riebel, T., Kömen, W.,
Braun, T., Tobin, J.F. \& Lee, S.J. 2004. Myostatin mutation associated with gross muscle hypertrophy in a child. The New England Journal of Medicine 350:26822688.

16.Clop, A., Marcq, F., Takeda, H., Pirottin, D., Tordoir, X., Bibe, B., Bouix, J., Caiment, F., Elsen, J.M., Eychenne, F., Larzul, C., Laville, E., Meish, F., Milenkovic, D., Tobin, J., Charlier, C. and Georges, M. 2006. A mutation creating a potential illegitimate microRNA target site in the Myostatin gene affects muscularity in sheep. Nature Genetics38:813-818.

17.Mosher, D.S., Quignon, P., Bustamante, C.D., Sutter, N.B., Mellersh, C.S., Parker, HG. \& Ostrander, E.A. 2007. A mutation in the myostatin gene increase muscle mass and enhances racing performance in heterozygote dogs. PLoS Genetics 3:779786.

18.Arthur, P.F. 1995. Double muscling in cattle. Australian Journal of Agricultural Research 46:1493-1515.

19.Boman, I.A., Klemetsdal, G., Blichfeldt, T., Nafstad, O. and Vage, D.I. 2009. A frame shift mutation in the coding region of the myostatin gene (MSTN) affects carcass conformation and fatness in Norwegian White Sheep (Ovisaries). Animal Genetics40:418-422.

20.Tobin, J.F. \& Celeste, A.J. 2005. Myostatin, a negative regulator of muscle mass: implications for muscle degenerative diseases. Current Opinion in Pharmacology 5:328-332.

\section{How to cite this article:}

Wani A. Ahad, Mudasir Andrabi, Sajad A. Beigh, Rumase A. Bhat and Riaz A. Shah. 2017. Applications of Myostatin (MSTN) Gene in the Livestock Animals and Humans: A Review. Int.J.Curr.Microbiol.App.Sci. 6(9): 1807-1811. doi: https://doi.org/10.20546/ijcmas.2017.609.222 